\title{
CATARACT SURGERY AND INTRAOCULAR LENS POWER CALCULATION IN A PATIENT WITH ANTERIOR MEGALOPHTHALMOS WITH NORMAL SIZED CRYSTALLINE LENS: CASE REPORT
}

\author{
Glisic Selimir, Jovanovic Milos, Gakovic Aleksandar, Dacic-Krnjaja Bojana \\ Eye Clinic, University of Belgrade, Clinical Center of Serbia, Belgrade, Serbia
}

Primljen/Received 03. 09. 2015. god.

Abstract: Cataract surgery and intraocular lens power calculation is challenging in patients with anterior megalophthalmos and cataract, with postoperative refractive surprise frequently reported. Deep anterior chamber in these patients substantially influence effective lens position. To minimize possibility of refractive surprise, we used Haigis formula that takes into account anterior chamber depth in the lens power calculation for our patient. Cataract was managed by phakoemulsification with standard intraocular lens implanted in the capsular bag. Postoperatively, satisfying refractive result was achieved and refractive surprise was avoided.

Key words: Anterior megalophthalmos, cataract surgery, intraocular lens, power calculation.

\section{INTRODUCTION}

Anterior megalophthalmos is a rare bilateral hereditary disorder in which megalocornea (defined as horizontal corneal diameter greater than $13 \mathrm{~mm}$ ) is associated with enlarged anterior segment of the eye (1). While in the simple megalocornea there are no additional ocular abnormalities, in the anterior megalophthalmos various other findings are present including iris hypoplasia, stromal atrophy, iris transillumination defects, pigment dispersion syndrome, myopia, cataract, lens subluxation and luxation, and glaucoma. Clinical diagnosis of anterior megalophthalmos can be confirmed by biometry findings of low vitreous index (vitreous length/axial length x100<69\%) (2).

Intraocular lens calculation is challenging in these patients, with postoperative hyperopic refraction frequently reported (3). Many commonly used formulas doesn't take into account anterior chamber depth (ACD) when calculating intraocular lens (IOL) power. This
Prihvaćen/Accepted 10. 10. 2015. god.

can cause erroneous estimation of effective lens position in these unusual eyes (8). We therefore used Haigis formula (9) to calculate IOL power in this particular patient, to minimize possibility of refractive surprise. Large capsular bag is often present in these eyes, adding inaccuracy in prediction of final IOL position, if in-the-bag placement is planed.

In this report we described a case of anterior megalophthalmos with normal-sized cataractous lens. Cataract was managed by phakoemulsification with standard intraocular lens implanted in the capsular bag. Postoperatively, satisfying refraction was achieved within $0.25 \mathrm{D}$ of targeted in both eyes.

\section{CASE REPORT}

A healthy 30-year-old man was referred to our department because of the bilateral vision loss due to advanced cataracts. His visual acuity was reduced to counting fingers at $1 \mathrm{~m}$ in the right eye, and at $3 \mathrm{~m}$ in the left.

Slit-lamp biomicroscopy of both eyes revealed signs of anterior megalophthalmos: enlarged corneas, deep anterior chamber, iris transillumination defects and white cataract in the right eye (Figure 1), while incipient in the left. Refraction of his right eye could not be obtained, and of the left eye was mildly myopic. Anterior segment biometry data was collected by Allegro Biograph (Wave Light) as follows: average keratometry OD: $37.79 \mathrm{D}(8.79 \mathrm{~mm} ; \mathrm{n}=1.332)$, and OS: 37.92 $\mathrm{D}(8.76 \mathrm{~mm} ; \mathrm{n}=1.332)$. Anterior chamber depth (ACD) and lens thickness (LT) for the right eye were $5.03 \mathrm{~mm}$ and $3.96 \mathrm{~mm}$, and for the left eye $5.21 \mathrm{~mm}$ and $4.05 \mathrm{~mm}$, respectively. Axial length of the right eye was $25.80 \mathrm{~mm}$, and $26.80 \mathrm{~mm}$ of the left, measured by immersion echography. Horizontal white-to-white 


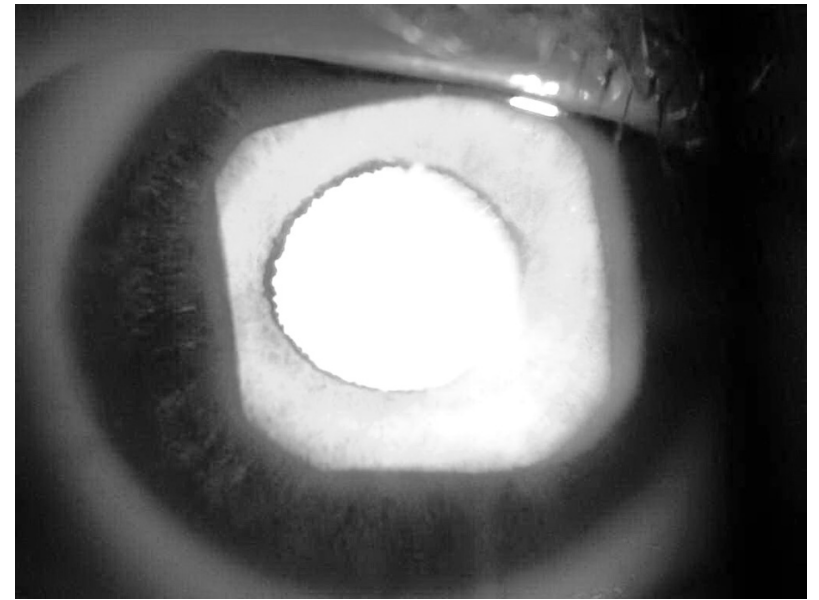

Figure 1. High magnification slit-lamp image of the anterior segment reveals white cataract and transillumination iris defects associated with anterior megalophthalmos

for the right and the left eye was $13.56 \mathrm{~mm}$ and 13.24 $\mathrm{mm}$, respectively. Intraocular pressure was $16 \mathrm{mmHg}$ bilaterally, measured by Goldmann applanation tonometer. There were no phacodonesis in any eye, but iridodonesis was present in both.

Calculated vitreous index was $65.15 \%$ for the right, and $65.45 \%$ for the left eye, confirming diagnosis of anterior megalophthalmos. UBM of the anterior segment revealed normal crystalline lens of $9.26 \mathrm{~mm}$ equatorial diameter in the right eye, concave iris configuration and elongated stretched zonules (Figure 2). Findings were similar for the left eye, with diameter of $9.24 \mathrm{~mm}$.

Power of the intraocular lens was estimated with various formulas utilizing Biograph proprietary software, aiming emmetropia. Haigis formula indicated 21.5D IOL for the right eye, while other formulas predicted lower power IOLs for emmetropia. Calculation for the left eye was 18.0D. Prediction error of some

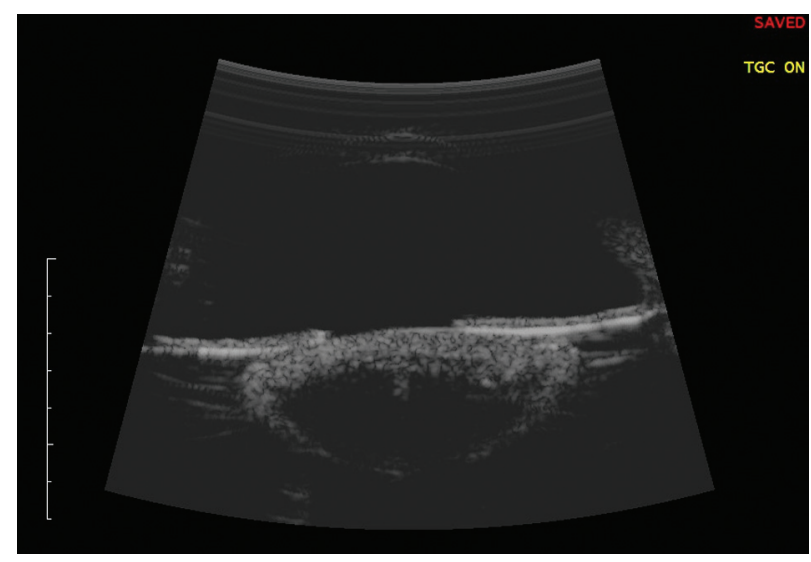

Figure 2. Preoperative UBM of the right eye showing deep anterior chamber, normal-sized crystalline lens with anterior cortical opacities, and elongated zonules
Table 1. Prediction of postoperative refraction of some commonly used formulas for SA60AT Acrysof lens. Input data (mm): AL 25.80, ACD 5.03, LT 3.96, Ave. K 8.79

\begin{tabular}{|c|c|c|c|c|c|}
\hline $\begin{array}{c}\text { IOL } \\
\text { power }\end{array}$ & SRK II & SRK T & Holladay I & Hoffer Q & $\begin{array}{c}\text { Haigis } \\
-0.091, \\
0.231, \\
118.8\end{array}$ \\
\hline 21.50 & -1.66 & -1.39 & -1.10 & -0.57 & 0.00 \\
\hline 21.00 & -1.26 & -1.00 & -0.73 & -0.22 & 0.35 \\
\hline 20.50 & -0.86 & -0.62 & -0.37 & 0.13 & 0.69 \\
\hline 20.00 & -0.46 & -0.25 & 0.00 & 0.47 & 1.03 \\
\hline 19.50 & -0.06 & 0.12 & 0.35 & 0.81 & 1.37 \\
\hline
\end{tabular}

Comment: All formulae except Haigis would suggest lower power IOL to achieve emmetropia, leading to hyperopic surprise.

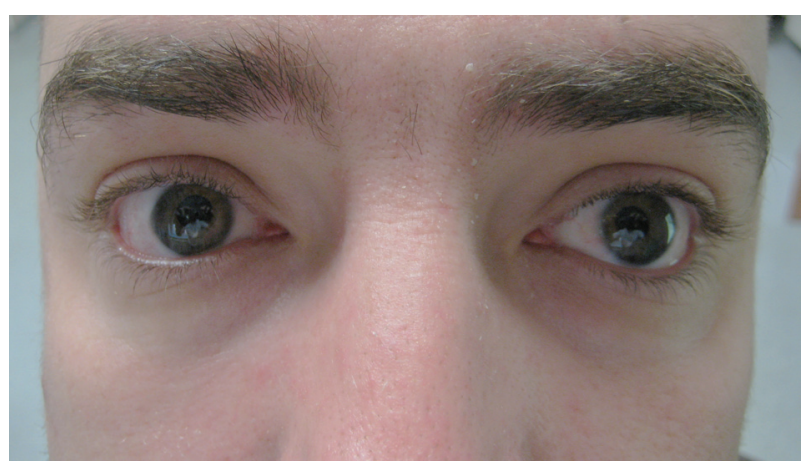

Figure 3. Postoperative appearance of both eyes

commonly used formulas for the patient right eye are listed in Table 1.

Cataract surgery of the right was performed in sub-Tenon anesthesia. Temporal clear corneal incision was made by $2.4 \mathrm{~mm}$ knife, anterior capsule was stained with trypan-blue dye, DisCoVisc viscoelastic was injected into the anterior chamber, paracenthesis incision was performed for second instrument placement, and continuous circular capsulorhexis was successfully finished. Viscoelastic material was added between iris and anterior capsule, to prevent lens iris diaphragm retropulsion syndrome (LIDRS), which is expected to occur in such a case. Phaco probe was inserted through the main incision and nucleus was chopped and aspirated. Cortical material was then aspirated with unimanual irrigation/aspiration handpiece. Single piece foldable intraocular lens Acrysof SA60AT (Alcon Laboratories, Inc.) of 21.5D was implanted in the capsular bag. Subsequently, viscoelastic material was removed and operative wounds were hydrated using balanced salt solution (BSS). A month later, second eye was operated in the same manner.

Postoperative course was unremarkable with both eyes. Best corrected visual acuity of the right eye reco- 


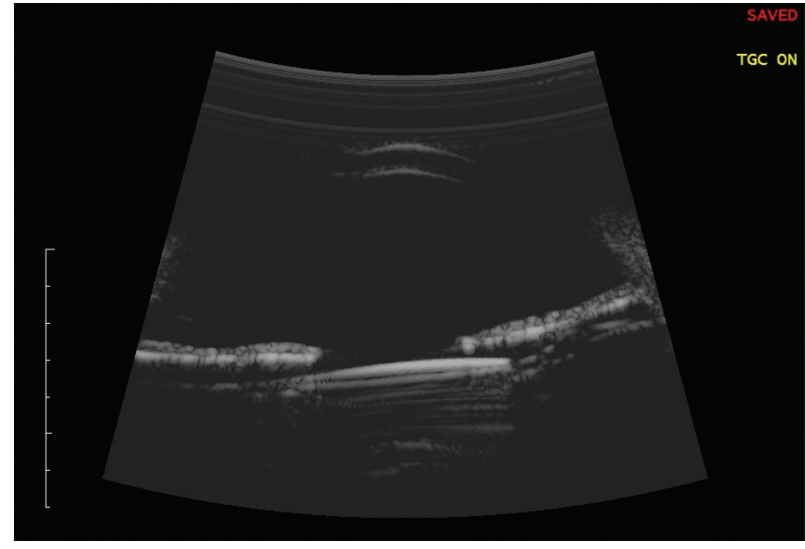

Figure 4. UBM of the operated eye shows in-the-bag position of the IOL

vered to 1,0 Snellen with -0.25 Dsph at the first postoperative visit and stayed so during 6 months of follow up. Postoperative spherical equivalent of the left eye was +0.25 Dsph, with uncorrected distance visual acuity of 1,0 Snellen at final exam 5 month after the surgery (Figure 3 and 4).

\section{DISCUSSION AND CONCLUSION}

Cataract extraction in eyes with anterior megalophthalmos is complex because of hyper-deep anterior chamber, zonular laxity and poor visualization. Enlargement of the ciliary ring is often associated with a wide capsular bag, so various methods to secure intraocular lens implant in these circumstances were described in literature: iris fixated artificial lens $(10,11)$, sutured posterior chamber IOL $(12,13)$, anterior capsulorhexis capture of the IOL (14), and custom-made intraocular lens with very wide haptic diameter (4). However, crystalline lens is not always large. Zare M.A. and colleagues (3) recently reported a case of normal-sized cataractous lens $(10,21 \mathrm{~mm})$ in an anteriorly-megalophthalmic eye, and they showed the significance of preoperative ultrasound biomicroscopy (UBM) imaging in cataract surgery planing in these patients.

Deep anterior chamber in patients with anterior megalophthalmos substantially influence effective lens position, so we used Haigis formula that takes into account ACD in the lens power calculation. Rather than using a single constant, the Haigis formula recommends IOL power based on a three-variable (a0, a1 and a2) function.

The $\mathrm{a} 0$, a 1 and $\mathrm{a} 2$ constants are set by optimizing a set of surgeon- and IOL-specific outcomes for a wide range of ALs and ACDs. By double-regression analysis, the a0, a1 and a 2 constants are adjusted to match the results for a specific surgeon and IOL. This means that the mathematics of the Haigis formula can be adjusted for each surgeon/IOL combination.
Normal size of the crystalline lens, as in our patient, allows secure and stabile in the bag placement of an IOL which, in turns, aids in accuracy of power calculation. Additional power adjustments are only needed if the IOL is planed to be iris -fixated or capsulorhexis captured, as is the cases with large or unstable capsular bag. One such a case was reported by Galvis V. and coauthors (10). Haigis formula was used in that case to calculate Artisan iris fixating lens power, with excellent refractive result.

Various other formulas are used to calculate IOL power, many of them are based only on two parameters, namely keratometry and axial length. This may explain hyperopic refractive result in some of these unusual eyes. On the other side, formulas that includes other relevant parameters (ACD, lens thickness, white-to-white measurement and other) like Haigis, Holladay II and Olsen (15), have a potential to more accurately predict postoperative refraction. In a case report of de Sanctis and Grignolo (16), Holladay II formula has been shown to be very accurate in their patient with X-linked megalocornea. Assia and coauthors (6) recently described a case of cataract surgery with IOL implantation in anterior megalophthalmos. After having hyperopic refractive surprise with SRK-T formula, they back-calculated IOL power using Holladay II formula, and concluded that IOL selection and refractive result would be similar. It remains unclear whether preoperative ACD was used in power calculation in that case. However, authors suggested the use of Holladay II formula to calculate IOL power in megalophthalmic eyes with very deep anterior chamber and wide WTW. Review of refractive results of reported cases of cataract surgery in eyes with anterior megalophthalmos, where IOL was placed in the capsular bag, is shown in Table 2.

Table 2. Previous and current reports of in-the-bag IOL placement in anterior megalophthalmos

\begin{tabular}{|c|c|c|}
\hline Author/year & Formula & Achieved refraction (SE) \\
\hline Zare, 2011 & SRK-T & $\mathrm{OD}+0.75 \mathrm{D}$ \\
\hline Marques Vaz, 2007 & $\mathrm{n} / \mathrm{a}$ & $\begin{array}{l}\mathrm{OD}+0.75 \mathrm{D} \\
\mathrm{OS}+1.75 \mathrm{D}\end{array}$ \\
\hline Assia, 2009 & SRK-T & $\begin{array}{l}\mathrm{OD}+2.25 \mathrm{D}(+2.90 \mathrm{D} \text { from target }) \\
\mathrm{OS}+1.00 \mathrm{D}(+2.25 \mathrm{D} \text { from target })\end{array}$ \\
\hline Hegde, 2012 & SRK II & $\mathrm{OD}+2.50 \mathrm{D}$ \\
\hline Javadi, 2000 & SRK-T & $\begin{array}{l}\text { 1. OD }-1.75 \mathrm{D} \\
\text { OS }-2.50 \mathrm{D} \\
\text { 2. OD }-0.825 \mathrm{D} \\
\text { OS }+0.25 \mathrm{D} \\
\text { 3. OS }-0.50 \mathrm{D}\end{array}$ \\
\hline Orczykowska, 2013 & SRK-T & $\mathrm{OS}+1.00 \mathrm{D}$ \\
\hline $\begin{array}{l}\text { De Sanctis and } \\
\text { Grignolo, } 2004\end{array}$ & Holladay II & $\begin{array}{l}\mathrm{OD}+0.48 \mathrm{D} \text { from target } \\
\mathrm{OS}-0.25 \mathrm{D} \text { from target }\end{array}$ \\
\hline Current, 2015 & Haigis & $\begin{array}{l}\text { OD }-0.25 \mathrm{D}(-0.25 \mathrm{D} \text { from target }) \\
\mathrm{OS}+0.25 \mathrm{D}(+0.25 \mathrm{D} \text { from target })\end{array}$ \\
\hline
\end{tabular}


There are fewer reports of myopic postoperative surprise. Javadi et al. (17) reported postoperative myopic surprise in the majority of their cases. Axial length was measured by ultrasound, but it wasn't stated wether it was accomplished by contact biometry, what may be the source of error. The other two published reports of myopic refraction after surgery are cases with sutured IOL, either through iris and capsule, or between iris and capsule $(12,13)$. Myopic refraction can be explained in these eyes by anterior shift of sutured IOL.

An interesting approach to IOL power calculation was utilized by Jain et al. (14). They used SRK II formula, and added $2 \mathrm{D}$ to emmetropic calculation. The IOL optic was sulcus fixated and captured through the capsulorhexis. Final refraction was emmetropic in one eye, and mildly myopic in the other.

We showed in our case that the error that may result from the classical formulas using only the K-reading and the axial length for the prediction of ELP can be avoided by using Haigis formula in these extreme eyes. Secure capsular bag fixation of the standard in- traocular lens provided stabile and satisfying refractive outcome.

\section{Financial disclosure}

No author has financial or proprietary interest in any product, method, or material mentioned in the article.
Abbreviations:
ACD - Anterior chamber depth
LT - Lens thickness
OD - Oculus dexter
OS - Oculus sinister
IOL - Intraocular lens
UBM - Ultrasound biomicroscopy
ELP - Effective lens position
WTW - White-to-white
BSS - Balanced salt solution
D - Diopter
K - Keratometry

LIDRS - Lens-iris diaphragm retropulsion syndrome

\title{
Sažetak
}

\section{OPERACIJA KATARAKTE I PRORAČUN DIOPTRIJSKE SNAGE INTRAOKULARNOG SOČIVA KOD PACIJENTA SA PREDNJIM MEGALOFTALMUSOM: PRIKAZ SLUČAJA}

\author{
Glisic Selimir, Jovanovic Milos, Gakovic Aleksandar, Dacic-Krnjaja Bojana \\ Eye Clinic, University of Belgrade, Clinical Center of Serbia, Belgrade, Serbia
}

Operacija katarakte i proračun dioptrijske snage intraokularnog sočiva kod pacijenata sa prednjim megaloftalmusom su veoma delikatni, a refraktivna iznenađenja su u literaturi često navođena. Duboka prednja očna komora kod ovih pacijenata značajno utiče na efektivni položaj implantiranog sočiva. Da bi smanjili mogućnost za neželjeni refraktivni ishod operacije katarakte, kod prikazanog pacijenta korišćena je Haigiso-

\section{REFERENCES:}

1. Duke-Elder S. Anomalies of the size of the cornea: Anterior megalophthalmos. In: Duke-Elder S, ed. System of Ophthalmology, vol. 3, pt 2: Normal and Abnormal Development; Congenital Deformities. St. Louis: Mosby, 1964. p. 498-505.

2. Meire FM, Delleman JW. Biometry in X-linked megalocornea: pathognomonic findings. Br J Ophthalmol. 1994; 78(10): 781-5.

3. Zare MA, Eshraghi B, Kiarudi MY, Masoule EA. Application of ultrasound biomicro-scopy in the planning of cataract surgery in anterior megalophthalmos. Indian J Ophthalmol. 2011; 59(5): 400-2. va formula koja uključuje parametar dubine prednje očne komore za kalkulaciju dioptrijske snage sočiva. Katarakta je operisana metodom fakoemulzifikacije, sa implantacijom veštačkog sočiva standardnih dimenzija u kapsularnu kesicu. Postoperativno je postignut zadovoljavajući refraktivni i funkcionalni rezultat.

Ključne reči: Prednji megaloftalmus, hirurgija katarakte, intraokularno sočivo, kalkulacija.

4. Vaz FM, Osher RH. Cataract surgery and anterior megalophthalmos: Custom intraocular lens and special consideration. J Cataract Refract Surg. 2007; 33(12): 2147-50.

5. Hegde V, Jain R, Bappal A. Successful Visual Rehabilitation in a Case of Anterior Megalophthalmos. Middle East Afr J Ophthalmol. 2012; 19(4): 413-5.

6. Assia EI, Segev F, Michaeli A. Cataract surgery in megalocornea; Comparison of 2 surgical approaches in a single patient. J Cataract Refract Surg. 2009; 35(12): 2042-6.

7. Orczykowska M, Omulecki W, Wilczyñski M. Cataract surgery in a patient with megalocornea - a case report. Klinika Oczna. 2013; 115(1): 53-6. 
8. Norrby S. Sources of error in intraocular lens power calculation. J Cataract Refract Surg. 2008; 34(8): 368-76.

9. Haigis W, Lege B, Miller N, Schneider B. Comparison of immersion ultrasound biometry and partial coherence interferometry for intraocular lens calculation according to Haigis. Graefes Arch Clin Exp Ophthalmol. 2000; 238(9): 765-73.

10. Galvis V, Tello A, Miotto G, Rangel CM. Artisan aphakic lens for cataract surgery in anterior megalophthalmos. Case Rep Ophthalmol. 2012; 3(3): 428-33.

11. Lee GA, Hann JV, Braga-Mele R. Phacoemulsification in anterior megalophthalmos. J Cataract Refract Surg. 2006; 32(7): 1081-4.

12. Dua HS, Azuara-Blanco A, Pillai CT. Cataract extraction and intraocular lens implantation in anterior megalophthalmos. J Cataract Refract Surg. 1999; 25(5): 716-9.

\section{Correspondence to /Autor za korespondenciju Dr Selimir Glišić}

Eye Clinic, University of Belgrade, Clinical Center of Serbia.

Pasterova 2, 11000 Belgrade, Serbia

e-mail: selimir.glisic@gmail.com
13. Sharan S, Billson FA. Anterior megalophthalmos in a family with 3 female siblings. J Cataract Refract Surg. 2005; 31(7): 1433-6.

14. Jain AK, Navani N, Singh R. PhacoemulsiWcation in anterior megalophthalmos: rhexis fixation technique for intraocular lens centration. Int Ophthalmol. 2014; 34(2): 279-84.

15. Olsen T. Prediction of the effective postoperative (intraocular lens) anterior chamber depth. J Cataract Refract Surg. 2006; 32(3): 419-24.

16. de Sanctis U, Grignolo FM. Cataract extraction in X-linked megalocornea; case report. Cornea. 2004; 23(5): 533-5.

17. Javadi MA, Jafarinasab MR, Mirdehghan SA. Cataract surgery and intraocular lens implantation in anterior megalophthalmos. J Cataract Refract Surg. 2000; 26(11): 1687-90. 